\title{
Carbon Nanotube-Induced Pulmonary Granulomatous Disease: Twist1 and Alveolar Macrophage M1 Activation
}

Barbara P. Barna ${ }^{1}$, Isham Huizar ${ }^{1, \dagger}$, Anagha Malur ${ }^{1}$, Matthew McPeek ${ }^{1}$, Irene Marshall ${ }^{1}$, Mark Jacob ${ }^{1}$, Larry Dobbs ${ }^{2}$, Mani S. Kavuru ${ }^{1,}$ and Mary Jane Thomassen ${ }^{1, *}$

1 Division or Pulmonary, Critical Care \& Sleep Medicine, East Carolina University, Brody Medical Sciences Building, 600 Moye Blvd. Rm. 3E-149, Greenville, NC 27834, USA; E-Mails: barnab@ecu.edu (B.P.B.); isham.huizar@ttuhsc.edu (I.H.); malura@ecu.edu (A.M.); mcpeekm07@students.ecu.edu (M.M.); marshalli@ecu.edu (I.M.); jacobm@ecu.edu (M.J.); mani.kavuru@jefferson.edu (M.S.K.)

2 Department of Pathology, East Carolina University, Brody Medical Sciences Building, 600 Moye Blvd. Rm.7S-10, Greenville, NC 27834, USA; E-Mail: dobbsl@ecu.edu

$\dagger$ Current Address: Division of Pulmonary and Critical Care Medicine, Texas Tech University Health Science Center, 3601 4th Street Mailstop 9410, Lubbock, TX 79430, USA.

* Current Address: Division of Pulmonary and Critical Care Medicine, Thomas Jefferson University, 834 Walnut Street, Suite 650, Philadelphia, PA 19107, USA.

* Author to whom correspondence should be addressed; E-Mail: thomassenm@ecu.edu; Tel.: +1-252-744-1117; Fax: +1-252-744-4887.

Received: 10 October 2013; in revised form: 14 November 2013 / Accepted: 15 November 2013 / Published: 6 December 2013

\begin{abstract}
Sarcoidosis, a chronic granulomatous disease of unknown cause, has been linked to several environmental risk factors, among which are some that may favor carbon nanotube formation. Using gene array data, we initially observed that bronchoalveolar lavage (BAL) cells from sarcoidosis patients displayed elevated mRNA of the transcription factor, Twist1, among many M1-associated genes compared to healthy controls. Based on this observation we hypothesized that Twist $1 \mathrm{mRNA}$ and protein expression might become elevated in alveolar macrophages from animals bearing granulomas induced by carbon nanotube instillation. To address this hypothesis, wild-type and macrophage-specific peroxisome proliferator-activated receptor gamma (PPAR $\gamma$ ) knock out mice were given oropharyngeal instillation of multiwall carbon nanotubes (MWCNT). BAL cells
\end{abstract}


obtained 60 days later exhibited significantly elevated Twist 1 mRNA expression in granuloma-bearing wild-type or PPAR $\gamma$ knock out alveolar macrophages compared to sham controls. Overall, Twist 1 expression levels in PPAR $\gamma$ knock out mice were higher than those of wild-type. Concurrently, BAL cells obtained from sarcoidosis patients and healthy controls validated gene array data: qPCR and protein analysis showed significantly elevated Twist 1 in sarcoidosis compared to healthy controls. In vitro studies of alveolar macrophages from healthy controls indicated that Twist 1 was inducible by classical (M1) macrophage activation stimuli (LPS, $T N F \alpha$ ) but not by IL-4, an inducer of alternative (M2) macrophage activation. Findings suggest that Twist 1 represents a PPAR $\gamma$-sensitive alveolar macrophage M1 biomarker which is induced by inflammatory granulomatous disease in the MWCNT model and in human sarcoidosis.

Keywords: Twist 1 ; alveolar macrophages; carbon nanotubes; sarcoidosis

\section{Introduction}

Pulmonary granulomas may appear in infectious or inflammatory disorders but may also be associated with environmental agents such as carbon nanotubes. Production of carbon nanomaterials for consumer products is expanding in worldwide commerce [1] and is an area of environmental concern. Combustion-generated multiwall carbon nanotubes (MWCNT) or nanoparticles may also be detectable in non-manufacturing environments, for example in vapors from diesel fuel, methane, propane and natural gas [2]. Data from experimental animal models illustrate the potential of carbon nanotubes to induce inflammatory changes, fibrosis, or granulomas [3-6].

In order to explore pathophysiologic mechanisms of granuloma formation and persistence, we developed a carbon nanotubes model of chronic granulomatous disease [7]. This novel murine model of MWCNT-elicited chronic granulomatous disease exhibits many similarities to the pathology of sarcoidosis, a prototypical human granulomatous disease of unknown etiology [8]. Sarcoidosis has been linked to some environmental risk factors that favor carbon nanotube formation in ambient air. Examples include exposure to wood-burning stoves, fireplaces, or firefighting [9-12]. Chronic granulomatous inflammation is prominent in the MWCNT model together with classically activated (M1) alveolar macrophages that over-express a number of proinflammatory genes [8]. In this model, granulomas persist out to 90 days, in contrast to previous sepharose bead models in which granulomas resolve within three weeks [13].

Sarcoidosis is characterized by marked elevation of $T$ Helper 1 (Th1) genes such as interferon gamma (IFN $\gamma)$ and $I L-12$ [14,15]. In such a milieu, alveolar macrophages appear classically activated (M1) and are major producers of the M1-associated gene, TNFa [16]. The transcription factor, peroxisome proliferator-activated receptor gamma (PPAR $\gamma$ ) is deficient in sarcoidosis alveolar macrophages compared to healthy controls, while the pro-inflammatory regulator, nuclear factor kappa B (NF- $\kappa \mathrm{B})$, is activated [17]. Healthy alveolar macrophages, unlike macrophages residing in other organs, express constitutively high levels of PPAR $\gamma$, suggesting a unique role for PPAR $\gamma$ in maintaining lung homeostasis [18]. PPAR $\gamma$, a well-studied regulator of glucose and lipid metabolism, 
is also a potent down-regulator of many pro-inflammatory pathways [19]. Recently, we found that macrophage-specific PPAR $\gamma$ deficiency exacerbated MWCNT-induced inflammation and granuloma formation, suggesting that PPAR $\gamma$ may also function as a negative regulator of chronic granulomatous disorders [20].

Twist proteins (Twist 1 and Twist2) are basic helix-loop-helix (bHLH) transcription factors present in many cell types and first recognized as important regulators of embryonic mesenchymal

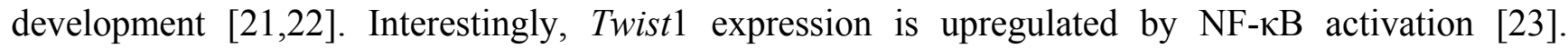
We initially noted elevated Twist 1 expression in sarcoidosis after analyzing gene array data from sarcoidosis and healthy control bronchoalveolar lavage (BAL) cells. We hypothesized that granulomatous disease might be a causative factor in Twist 1 expression and utilized our MWCNT model to explore this issue. Further, we hypothesized that Twist 1 would be elevated by M1 but not an inducer of alternative (M2) stimuli. Findings confirmed our hypothesis by indicating that induction of inflammatory granulomatous disease elevates Twist1 gene and protein expression in alveolar macrophages and that elevated Twist 1 expression is associated with M1 activation.

\section{Results and Discussion}

\subsection{Sarcoidosis Patients Display an M1 Profile in Bronchoalveolar Lavage}

Microarray results indicated a prevalence of significantly upregulated M1 genes in sarcoidosis BAL as anticipated, based upon previous reports citing elevated $I F N \gamma$ pathways in sarcoidosis lung [24] (Table 1). A sample of M2 associated genes showed no significant elevation from healthy control levels with the exception of CCL2 which has been noted previously in sarcoidosis [25,26]. Data also confirmed our previous report showing elevated $I F N \gamma$ in sarcoidosis BAL cells [27], as well as other reports of elevated STAT1 [24,28]. IL-12, which is also elevated in sarcoidosis lung [29,30], promotes STAT4 activation and Th1 development [31,32]. M1 associated IFN $\gamma$ inducible chemokines (CXCL 9, 10, 11 and CCL5) were also elevated as previously reported [26,33,34].

Table 1. M1 and M2-associated genes in Sarcoidosis gene array samples.

\begin{tabular}{llc}
\hline Gene Symbol & \multicolumn{1}{c}{ Gene Name } & Fold Change \\
\hline \multicolumn{1}{c}{ M1-associated Genes } \\
\hline IFNy & Interferon-gamma & 7.13 \\
IL6 & Interleukin 6 & 2.83 \\
IL18R1 & Interleukin 18 receptor 1 & 4.59 \\
IL12Rb2 & Interleukin 12 receptor, beta 2 & 6.32 \\
STAT1 & Signal transducers and activators of transcription 1 & 2.05 \\
STAT4 & Signal transducers and activators of transcription 4 & 3.82 \\
CXCL11 & Interferon inducible T cell a chemoattractant (I-TAC) & 3.93 \\
CXCL10 & Interferon inducible protein 10, (IP-10) & 3.48 \\
CXCL9 & Monokine induced by interferon $\gamma,(M I G)$ & 4.64 \\
CCL5 & Chemokine (C-C motif) (RANTES) & 5.77 \\
\hline
\end{tabular}


Table 1. Cont.

\begin{tabular}{|c|c|c|}
\hline Gene Symbol & Gene Name & Fold Change \\
\hline \multicolumn{3}{|c|}{ M2-associated Genes } \\
\hline IL10 & Interleukin 10 & NS * \\
\hline$I L 1 R A$ & Interleukin-1 receptor antagonist & NS * \\
\hline$C D 36$ & Member of the class B scavenger receptor & NS * \\
\hline$M M P 2$ & Matrix metalloproteinase 2 & NS * \\
\hline$M M P 7$ & Matrix metalloproteinase 7 & NS * \\
\hline CCL24 & Chemokine (C-C motif) ligand 24 & -5.35 \\
\hline$C C L 2$ & Chemokine (C-C motif) ligand 2 & 2.71 \\
\hline
\end{tabular}

\subsection{Twist1 is Elevated in Sarcoidosis Alveolar Macrophages}

Microarray studies also indicated a 5.1-fold increase in Twist 1 (Probe set ID\# 213943_at) expression in BAL cells from sarcoidosis patients compared to healthy controls. The false discovery rate was significantly low (0.04\%). QPCR validated array data and demonstrated significant elevation of Twist 1 expression in sarcoidosis patient BAL cells compared to healthy controls (Figure 1A). This observation was confirmed by immunostaining. No Twist 1 staining was detectable in alveolar macrophages of healthy controls (Figure 1B). Evaluation of Twist 1 protein in sarcoidosis BAL cells (Figure 1C) indicated elevated Twist 1 in alveolar macrophages.

Figure 1. (A-C). Twist 1 in human alveolar macrophages. Twist 1 mRNA expression is intrinsically elevated in alveolar macrophages of sarcoidosis patients compared to healthy controls (A); Immunostaining did not detect Twist 1 protein expression in healthy control alveolar macrophages (B) but Twist 1 protein appears in alveolar macrophages of sarcoidosis patients; scale bar $=50 \mu \mathrm{m}(\mathbf{C})$. Cells were counterstained with propidium iodide to highlight nuclei (same magnification as Figure 1B). Images are representative of findings from three patients and three controls.

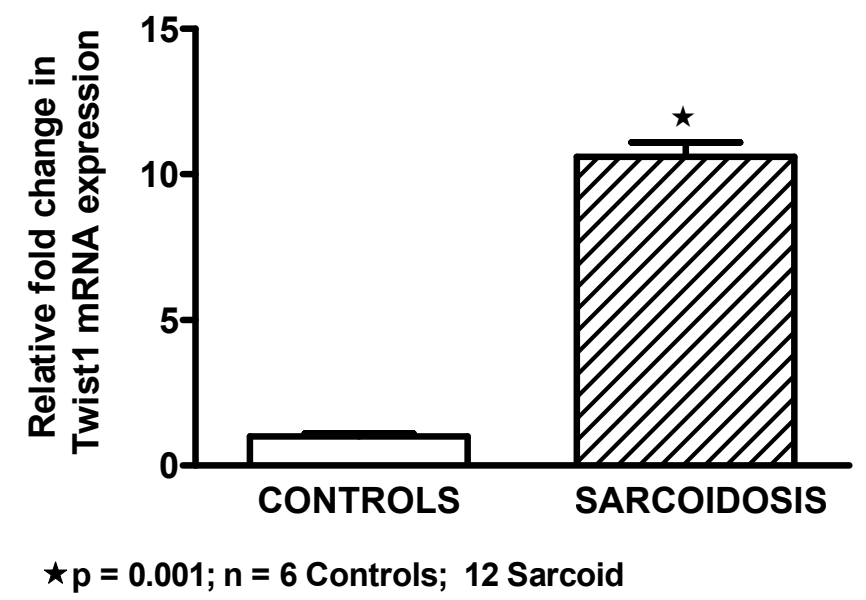

(A) 
Figure 1. Cont.

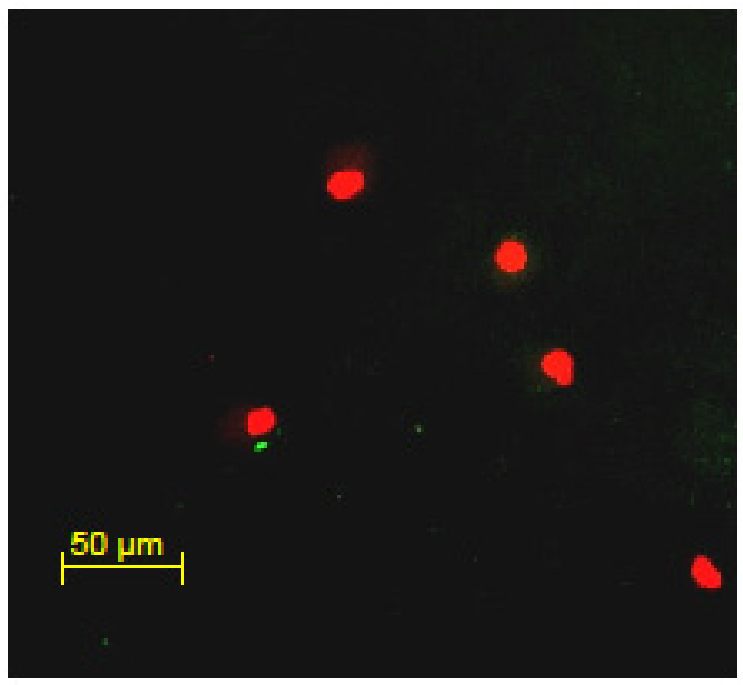

(B)

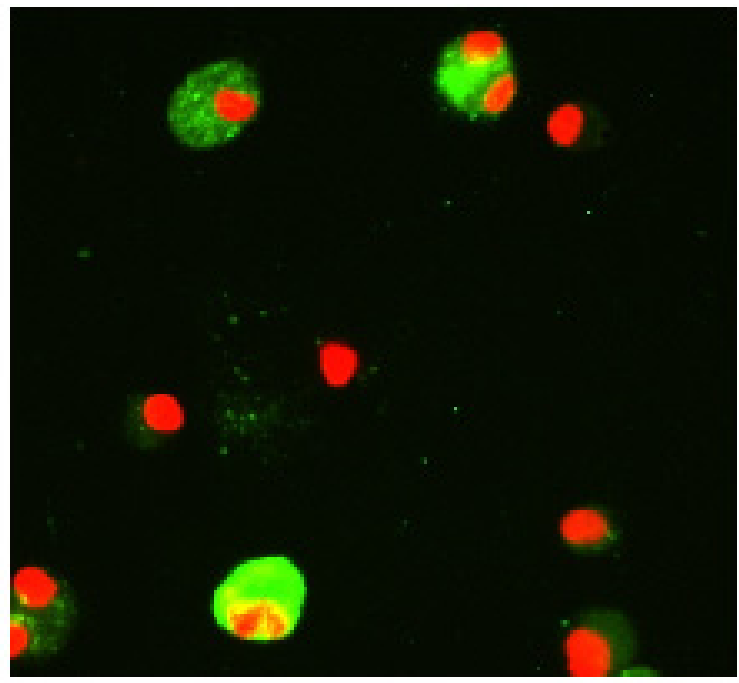

(C)

\subsection{Macrophage M1 Inducers Upregulate Twist1}

Because of the striking M1 profile of sarcoidosis BAL cells, we hypothesized that Twist 1 might also be an M1 biomarker. To address this issue, we obtained BAL cells from healthy individuals and cultured alveolar macrophages in vitro with each of three classic M1 inducers: the TLR4 ligand, LPS; TLR1-2 ligand, PAM3-CSK4; and the pro-inflammatory cytokine, TNF $[35,36]$. Results indicated that all three reagents significantly upregulated alveolar macrophage Twist 1 expression compared to control medium alone (Figure $2 \mathrm{~A}-\mathrm{C})$. Cultures $(n=4)$ with the M2-associated inducer, $I L-4$, did not result in elevated Twist 1 (data not shown).

Figure 2. (A-C). Upregulation of Twist 1 mRNA is found in healthy control alveolar macrophages exposed in vitro to M1 activators, LPS (A); PAM3-CSK4 (B); and TNF $\alpha(\mathbf{C})$.

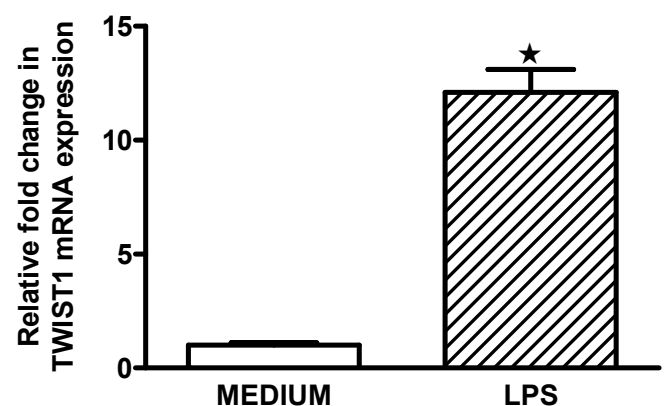

$\star \mathrm{p}=0.0006 ; \mathrm{n}=6$

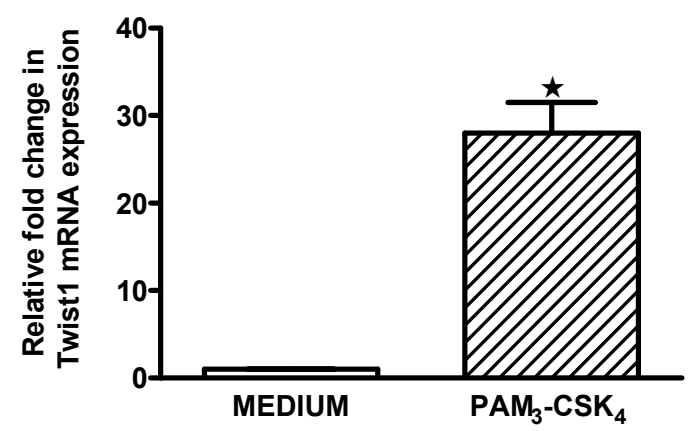

$\star_{p}=0.04 ; n=3$

(A)

(B) 
Figure 2. Cont.

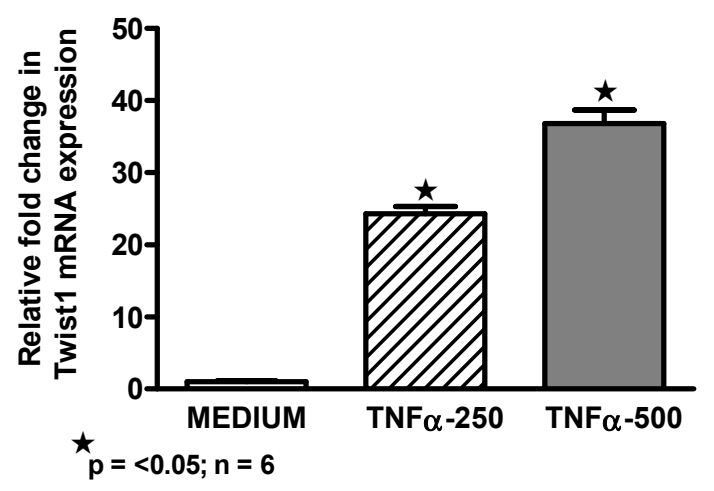

(C)

\subsection{Twist1 Is Elevated in Alveolar Macrophages from MWCNT-Granuloma Bearing Mice}

To determine if granulomatous disease was a factor in Twist 1 upregulation, wild-type C57B1/6 mice and macrophage specific PPAR $\gamma$ knock out mice were instilled with MWCNT and euthanized 60 days later. By 60 days, pulmonary granulomas containing MWCNT are prominent in this model [20]. Macrophage specific PPAR $\gamma$ knock out mice were included because our previous report had observed increased granulomas in this group [20]. In addition our sarcoidosis studies had indicated PPAR $\gamma$ deficiency in sarcoidosis alveolar macrophages [17,27]. Compared to sham controls, significant elevation of BAL cell Twist 1 mRNA expression was observed after MWCNT-treatment in both C57B1/6 wild-type (4.0 \pm 0.1 fold change) and macrophage specific PPAR $\gamma$ knock out ( $6.5 \pm 0.2$ fold change) mice (Figure 3A). In untreated mice, Twist $1 \mathrm{mRNA}$ expression was intrinsically elevated in PPAR $\gamma$ knock out mice compared to wild-type (Figure 3B). Examination of immunostained BAL cytospins from wild-type mice also indicated elevation of Twist 1 protein after MWCNT treatment (Figure 3D) compared to sham-treated animals (Figure 3C).

\subsection{Discussion}

Findings suggest that alveolar macrophage Twist 1 expression is upregulated by inflammatory granulomatous disease and by PPAR $\gamma$ deficiency. Our previous studies have shown that PPAR $\gamma$ becomes deficient in alveolar macrophages from MWCNT-treated wild-type mice [20]. The coincidence of elevated Twist 1 and PPAR $\gamma$ deficiency in alveolar macrophages from macrophage-specific PPAR $\gamma$ null mice, MWCNT-instilled wild-type mice, and PPAR $\gamma$-deficient sarcoidosis patients is an intriguing observation not previously reported. In fibroblasts and macrophages, Twist expression has been reported to be promoted by $T N F \alpha$ [23,37], and our results support those findings. Many studies have cited evidence for elevated $T N F \alpha$ in sarcoidosis patients [38-40]. $T N F \alpha$ is also produced in the MWCNT granuloma model [7]. Thus the inflammatory milieu of both sarcoidosis and MWCNT granulomatous disease contains inducers of Twist 1 expression. Twist 1 has also been observed in fibroblasts and epithelial cells within fibrotic foci from lung tissues of patients with idiopathic pulmonary fibrosis [41,42]. Further, Twist 1 expression in these cells could be induced in vitro by pro-fibrotic growth factors or viral infection, respectively $[41,42]$. Collectively, such results suggest that cellular patterns of Twist 1 expression may vary with disease pathology. 
Figure 3. Twist 1 in murine alveolar macrophages. Bronchoalveolar lavage (BAL) cells were obtained from C57B1/6 wild-type and macrophage specific PPAR $\gamma \mathrm{KO}$ mice at 60 days after oropharyngeal instillation of MWCNT. At this time point, all animals have extensive granulomatous disease in the lung [7,20]. Twist $1 \mathrm{mRNA}$ is elevated in BAL cells from MWCNT-treated wild-type $(n=7)$ mice versus sham controls $(n=6)$ as well as in MWCNT-treated macrophage specific PPAR $\gamma$ KO mice $(n=11)$ compared to sham controls $(n=7)$ (A); Twist 1 mRNA is intrinsically elevated in BAL from untreated PPAR $\gamma \mathrm{KO}$ mice compared to untreated wild-type controls (B); Immunostaining of alveolar macrophages from wild-type $\mathrm{C} 57 \mathrm{Bl} / 6$ mice does not detect Twist 1 protein after sham-treatment. Scale bar $=5 \mu \mathrm{m}$. (C); but shows elevated Twist 1 protein after MWCNT instillation (same magnification as Figure 3C) (D).

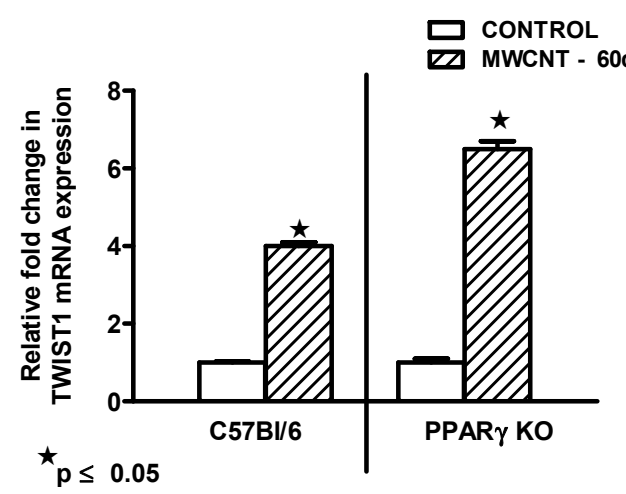

(A)

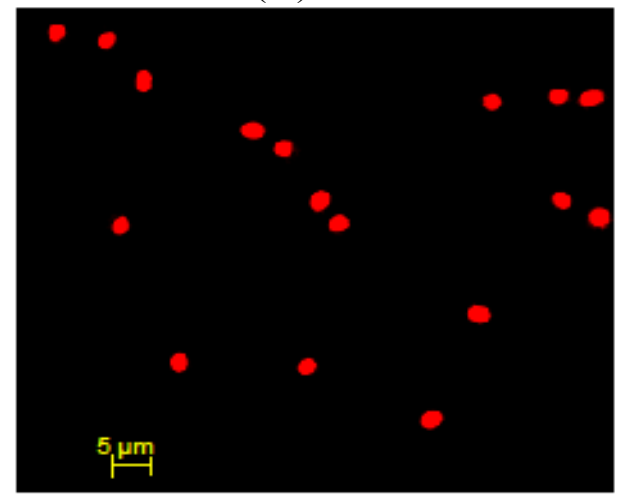

(C)

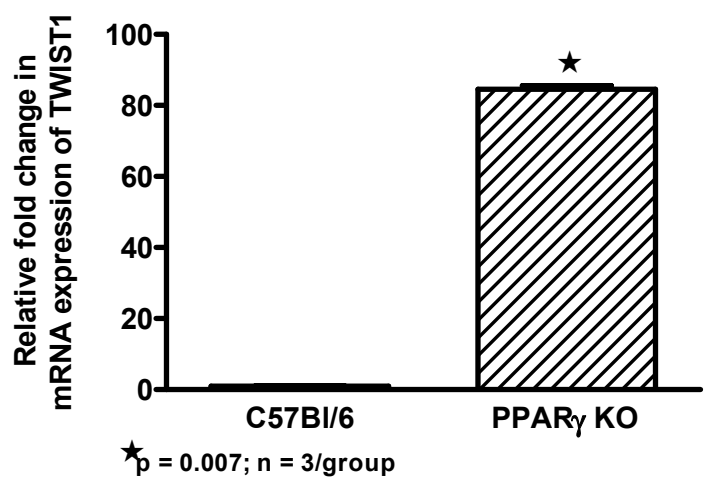

(B)

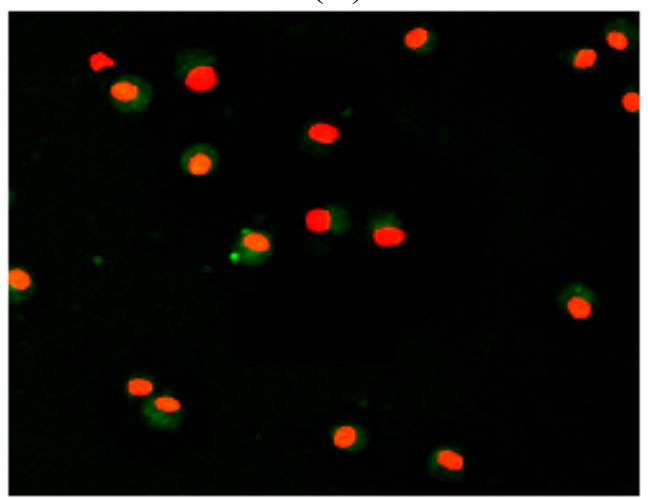

(D)

The current results also suggest that Twist 1 may represent an M1 marker of alveolar macrophage activation. Classical (M1) activation can be driven by TLR ligands (reviewed in [36]). Both TLR ligands LPS and PAM3-CSK4 significantly increased Twist 1 in alveolar macrophages from healthy donors. LPS appears to induce healthy alveolar macrophages to express an M1 phenotype with a transcription factor scenario (reduced PPAR $\gamma$ together with elevated NF- $\mathrm{BB}$ and Twist 1 ) that resembles the phenotype of sarcoidosis alveolar macrophages [17,27] as well as that of MWCNT-instilled mice [20]. It should be noted that PPAR $\gamma$ is also an activator of alternative (M2) macrophage activation [43]. Thus the reduction of alveolar macrophage PPAR $\gamma$ noted in both sarcoidosis and MWCNT-instilled mice would most likely favor a M1 phenotype.

The functional consequences of Twist 1 expression in alveolar macrophages remain to be explored. Twist 1 , a transcription factor that plays a vital role in formation of embryonic mesenchymal tissue, also 
appears in many types of mature cells [21,22]. Studies of Twist 1 in mature cells are few and none have focused on alveolar macrophages. Investigations of rat lung fibroblasts indicate that Twist 1 overexpression protects cells against apoptosis [41,42]. Other evidence suggests that Twist proteins may be NF- $\kappa \mathrm{B}$ regulators. Deficiency or haplo-insufficiency of Twist proteins produces a lethal systemic inflammatory syndrome [23]. Twist expression is upregulated by NF- $\kappa \mathrm{B}$ activation and Twist proteins may provide negative feedback by blocking p65/RelA-mediated transactivation, thus

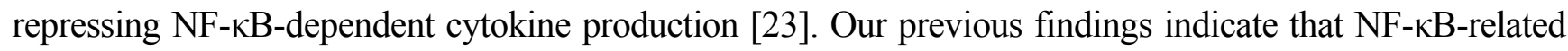
pro-inflammatory cytokines are elevated in MWCNT-instilled mice, thus suggesting a setting with

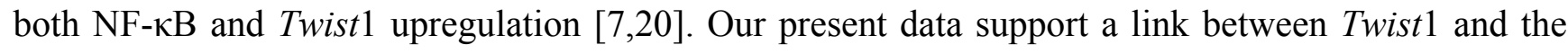
M1 macrophage activation phenotype in alveolar macrophages. The functional significance of alveolar macrophage Twist 1 expression in MWCNT-induced granulomatous disease, however, must be determined in future studies.

\section{Experimental Section}

\subsection{Human Study Population}

Sarcoidosis subjects $(n=23)$ were recruited from patients undergoing routine clinical evaluation for initial diagnosis (12) or confirmation (11) of sarcoidosis (Table 2). None had Löfgren's syndrome [44]. All diagnoses were confirmed by pulmonary histology demonstrating non-necrotizing granulomas in the absence of infection or other etiologies.

Table 2. Demographics of Patients and Control Subjects.

\begin{tabular}{lcc}
\hline \multirow{2}{*}{ Characteristics } & Sarcoidosis & Healthy Controls \\
\cline { 2 - 3 } \cline { 2 - 3 } Age (year) & $(\boldsymbol{n}=\mathbf{2 3})$ & $(\boldsymbol{n}=\mathbf{2 7})$ \\
Gender & $44.8 \pm 2.6$ & $32.4 \pm 1.4$ \\
Self-reported race & $15 \mathrm{~F} / 8 \mathrm{M}$ & $18 \mathrm{~F} / 9 \mathrm{M}$ \\
Smokers & $21 \mathrm{AA} / 2 \mathrm{C}$ & $14 \mathrm{AA} / 12 \mathrm{C} / 1 \mathrm{AI}$ \\
FVC \% predicted & $(10$ exsmokers $)$ & 0 (1 exsmokers) \\
CXR stage: 0-1 & $80.6 \pm 3.8$ & - \\
CXR stage: 2-4 & $6 *$ & - \\
BAL Macrophages (\%) & 16 & - \\
BAL Lymphocytes (\%) & $83.3 \pm 2.8$ & $95.5 \pm 0.6$ \\
BAL PMNs (\%) & $15.2 \pm 2.8$ & $4.0 \pm 0.6$ \\
& $1.6 \pm 1.0$ & $0.4 \pm 0.2$ \\
Main treatment indication(s) at time of bronchoscopy & Not treated (11) & - \\
Organ involvement & pulmonary (9) & \\
\hline
\end{tabular}

* no radiographs $(1) ; * *$ ocular, cardiac, dermal, neuro, hepatic, splenic. 
The healthy control group $(n=27)$ was composed of individuals with no history of lung disease and no medication usage at time of bronchoscopy (Table 2). These individuals volunteered to undergo bronchoscopy as part of an Institutional Review Board-approved research program (Greenville, NC, USA). The protocol was approved by the East Carolina University Institutional Review Board (Greenville, NC, USA) and written informed consent was obtained from all patient and control subjects.

\subsection{Human Cell Collection and Culture}

Bronchoalveolar lavage (BAL) cells were collected by fiberoptic bronchoscopy as previously described [17]. Differential cell counts were obtained from cytospins stained with modified Wright's stain (Fisher Scientific, Kalamazoo, MI, USA). Mean viability of lavage cells was greater than 95\% as determined by trypan blue dye exclusion. For culture, BAL cells were plated into 24-well plates (300,000 alveolar macrophages/well) or chamber slides $(60,000$ cells/well) in RPMI 1640 medium supplemented with 5\% human AB serum (Gemini, Calabasas, CA, USA), L-glutamine, and antibiotics as described previously [45]. Adherence purified alveolar macrophages (60 min) were cultured for $24 \mathrm{~h}$ in medium alone, or medium supplemented with LPS (Salmonella typhimurium, Sigma, St. Louis, MO, USA) (500 ng/mL), PAM3-CSK4 (50 ng/mL) (Fisher Scientific, Waltham, MA, USA), TNF $\alpha$ (250-500 units $/ \mathrm{mL})$, or IL-4 (10 ng/mL) (R \& D Systems, Minneapolis, MN, USA). Yields of patient or control BAL cells were not sufficient to allow performance of all experiments on each individual specimen.

\subsection{Immunocytochemistry}

Immunocytochemistry was performed on cytospin preparations from freshly isolated human or murine alveolar macrophages for Twist 1 basal expression levels (Santa Cruz Biotech, Santa Cruz, CA, USA). Slides were fixed with 4\% paraformaldehyde-PBS, then permeabilized with Triton X-100 and stained with anti-TWIST1 antibody (C-17, Santa Cruz, CA, USA) at 1:500 dilution, followed by Alexa conjugated goat anti rabbit IgG (Invitrogen, Carlsbad, CA, USA). Murine cells were stained similarly using anti-TWIST1 (H-81, Santa Cruz, CA, USA). Slides were counter stained with Propidium Iodide (PI) (Vector Laboratories, Burlingame, CA, USA) to facilitate nuclear localization.

\subsection{Microarray Analysis}

Microarray analyses of BAL cells from 12 sarcoidosis patients not on steroids and 10 healthy control individuals were carried out by Expression Analysis, Inc. (Durham, NC, USA) using the Affymetrix Human Genome GeneChip U133A 2.0 Array Plate (Affymetrix, Santa Clara, CA, USA). This array plate measures 14,500 well-characterized genes per sample. Total RNA was extracted from BAL samples and RNA quality was verified by the Agilent 2100 bioanalyzer (Agilent Technologies, Santa Clara, CA, USA). Amplified biotin-labeled cRNA was generated from $2 \mu \mathrm{g}$ of total RNA. Fragmented cRNA was hybridized to gene chip arrays (Affymetrix, Santa Clara, CA, USA) according to the manufacturer's instructions, then stained, washed and scanned. Principal component analysis (PCA) was conducted on all genes. Gene expression differences of patients versus controls were assessed by means of Student's $t$-test, with a false discovery rate (FDR) correction for multiple testing 
(R Bioconductor, R Series, Seattle, WA, USA). Genes with a false discovery rate $\leq 0.05$ and a fold change $\geq 2$ were considered differentially expressed.

\subsection{Quantitative $m R N A$ Expression}

Total RNA was extracted from human or murine cells by RNeasy protocol (Qiagen, Valencia, CA, USA). Expression of mRNA was determined by real time qPCR using the ABI Prism 7300 Detection System (TaqMan; Applied Biosystems, Foster City, CA, USA). Primer-probe sets for TWIST1 and a housekeeping gene $(G A P D H)$ were obtained from Qiagen, Germantown, MD, USA. Data were expressed as a fold change in mRNA expression compared to control values [46].

\subsection{Murine MWCNT Model}

All studies were conducted in conformity with Public Health Service (PHS) Policy on humane care and use of laboratory animals and were approved by the institutional animal care committee. C57BL/6J wild-type mice and macrophage specific PPAR $\gamma \mathrm{KO}$ conditional mice received an oropharyngeal instillation of MWCNT (100 $\mu \mathrm{g}$ in surfactant/PBS) after sedation with isofluorane. Sixty days after sham (surfactant in PBS) or MWCNT treatment, mice were sacrificed, and bronchoalveolar lavage (BAL) or lungs were harvested for further analysis as previously described [7].

\subsection{Characterization of Carbon Nanotubes}

MWCNTs (catalogue number 900-1501, lot GS1801) were obtained from SES Research (Houston, TX, USA). Scanning electron microscopy (Hitachi, Tokyo, Japan) was used to determine the structural characteristics of MWCNTs. Nitrogen adsorption studies were carried out using a physisorption analyzer (ASAP 2010; Micromeritics, Norcross, GA, USA). Full details of MWCNT characterization have been described previously [7].

\subsection{Statistical Analyses}

QPCR data were analyzed by one-way analysis of variance (ANOVA) and Tukey's test using Prism software (GraphPad, Inc., San Diego, CA, USA). Data from in vitro studies were evaluated by Students $t$-test.

\section{Conclusions}

Current findings suggest that alveolar macrophages exhibit Twist 1 expression when an M1 stimulatory milieu, as found in chronic granulomatous disease, dysregulates pulmonary homeostasis. Application of the MWCNT granuloma model will be a useful tool to explore the potential interactions of Twist 1 with the transcription factors, NF- $\kappa \mathrm{B}$ and PPAR $\gamma$ in subsequent studies of pulmonary granulomatous disease.

\section{Acknowledgments}

This project was supported in part by HL 077652 and ES022462 to Thomassen, MJ. 


\section{Conflicts of Interest}

The authors declare no conflict of interest.

\section{References}

1. De Volder, M.F.; Tawfick, S.H.; Baughman, R.H.; Hart, A.J. Carbon nanotubes: Present and future commercial applications. Science 2013, 339, 535-539.

2. Lam, C.W.; James, J.T.; McCluskey, R.; Arepalli, S.; Hunter, R.L. A review of carbon nanotube toxicity and assessment of potential occupational and environmental health risks. Crit. Rev. Toxicol. 2006, 36, 189-217.

3. Bonner, J.C. Carbon nanotubes as delivery systems for respiratory disease: Do the dangers outweigh the potential benefits? Expert Rev. Respir. Med. 2011, 5, 779-787.

4. Shvedova, A.A.; Kisin, E.R.; Mercer, R.; Murray, A.R.; Johnson, V.J.; Potapovich, A.I.; Tyurina, Y.Y.; Gorelik, O.; Arepalli, S.; Schwegler-Berry, D.; et al. Unusual inflammatory and fibrogenic pulmonary responses to single-walled carbon nanotubes in mice. Am. J. Physiol. Lung Cell Mol. Physiol. 2005, 289, L698-L708.

5. Mercer, R.R.; Hubbs, A.F.; Scabilloni, J.F.; Wang, L.; Battelli, L.A.; Friend, S.; Castranova, V.; Porter, D.W. Pulmonary fibrotic response to aspiration of multi-walled carbon nanotubes. Part. Fibre Toxicol. 2011, doi:10.1186/1743-8977-8-21.

6. Wang, X.; Katwa, P.; Podila, R.; Chen, P.; Ke, P.C.; Rao, A.M.; Walters, D.M.; Wingard, C.J.; Brown, J.M. Multi-walled carbon nanotube instillation impairs pulmonary function in C57BL/6 mice. Part. Fibre Toxicol. 2011, doi:10.1186/1743-8977-8-24.

7. Huizar, I.; Malur, A.; Midgette, Y.A.; Kukoly, C.; Chen, P.; Ke, P.C.; Podila, R.; Rao, A.M.; Wingard, C.J.; Dobbs, L.; et al. Novel murine model of chronic granulomatous lung inflammation elicited by carbon nanotubes. Am. J. Respir. Cell Mol. Biol. 2011, 45, 858-866.

8. Chen, E.S.; Moller, D.R. Sarcoidosis-Scientific progress and clinical challenges. Nat. Rev. Rheumatol. 2011, 7, 457-467.

9. Bresnitz, E.A.; Stolley, P.D.; Israel, H.L.; Soper, K. Possible risk factors for sarcoidosis: A case-control study. Ann. N. Y. Acad. Sci. 1986, 465, 632-642.

10. Prezant, D.J.; Dhala, A.; Goldstein, A.; Janus, D.; Ortiz, F.; Aldrich, T.K.; Kelly, K.J. The incidence, prevalence, and severity of sarcoidosis in New York city firefighters. Chest 1999, 116, 1183-1193.

11. Izbicki, G.; Chavko, R.; Banauch, G.I.; Weiden, M.D.; Berger, K.I.; Aldrich, T.K.; Hall, C.; Kelly, K.J.; Prezant, D.J. World trade center "sarcoid-like" granulomatous pulmonary disease in New York city fire department rescue workers. Chest 2007, 131, 1414-1423.

12. Wu, M.; Gordon, R.E.; Herbert, R.; Padilla, M.; Moline, J.; Mendelson, D.; Litle, V.; Travis, W.D.; Gil, J. Case report: Lung disease in World Trade Center responders exposed to dust and smoke. Carbon nanotubes found in the lungs of World Trade Center patients and dust samples. Environ. Health Perspect. 2010, 118, 499-504.

13. Kunkel, S.; Lukacs, N.W.; Strieter, R.M.; Chensue, S.W. Animal models of granulomatous inflammation. Semin. Respir. Infect. 1998, 13, 221-228. 
14. Shigehara, K.; Shijubo, N.; Ohmichi, M.; Takahashi, R.; Kon, S.; Okamura, H.; Kurimoto, M.; Hiraga, Y.; Tatsuno, T.; Abe, S.; et al. IL-12 and IL-18 are increased and stimulate IFN- $\gamma$ production in sarcoid lungs. J. Immunol. 2001, 166, 642-649.

15. Zissel, G.; Prasse, A.; Muller-Quernheim, J. Sarcoidosis-Immunopathogenetic concepts. Semin. Respir. Crit. Care Med. 2007, 28, 3-14.

16. Fehrenbach, H.; Zissel, G.; Goldmann, T.; Tschernig, T.; Vollmer, E.; Pabst, R.; Muller-Quernheim, J. Alveolar macrophages are the main source for tumour necrosis factor-alpha in patients with sarcoidosis. Eur. Respir. J. 2003, 21, 421-428.

17. Culver, D.A.; Barna, B.P.; Raychaudhuri, B.; Bonfield, T.L.; Abraham, S.; Malur, A.; Farver, C.F.; Kavuru, M.S.; Thomassen, M.J. Peroxisome proliferator-activated receptor gamma activity is deficient in alveolar macrophages in pulmonary sarcoidosis. Am. J. Respir. Cell. Mol. Biol. 2004, 30, 1-5.

18. Bonfield, T.L.; Farver, C.F.; Barna, B.P.; Malur, A.; Abraham, S.; Raychaudhuri, B.; Kavuru, M.S.; Thomassen, M.J. Peroxisome proliferator-activated receptor-gamma is deficient in alveolar macrophages from patients with alveolar proteinosis. Am. J. Respir. Cell Mol. Biol. 2003, $29,677-682$.

19. Straus, D.S.; Glass, C.K. Anti-inflammatory actions of PPAR ligands: New insights on cellular and molecular mechanisms. Trends Immunol. 2007, 28, 551-558.

20. Huizar, I.; Malur, A.; Patel, J.; McPeek, M.; Dobbs, L.; Wingard, C.; Barna, B.P.; Thomassen, M.J. The role of PPAR $\gamma$ in carbon nanotube-elicited granulomatous lung inflammation. Respir. Res. 2013, doi:10.1186/1465-9921-14-7.

21. Thisse, B.; El, M.M.; Perrin-Schmitt, F. The twist gene: Isolation of a Drosophila zygotic gene necessary for the establishment of dorsoventral pattern. Nucleic Acids Res. 1987, 15, 3439-3453.

22. Franco, H.L.; Casasnovas, J.; Rodriguez-Medina, J.R.; Cadilla, C.L. Redundant or separate entities?-Roles of Twist1 and Twist2 as molecular switches during gene transcription. Nucleic Acids Res. 2011, 39, 1177-1186.

23. Sosic, D.; Richardson, J.A.; Yu, K.; Ornitz, D.M.; Olson, E.N. Twist regulates cytokine gene expression through a negative feedback loop that represses NF- $\gamma \mathrm{B}$ activity. Cell 2003, 112, 169-180.

24. Crouser, E.D.; Culver, D.A.; Knox, K.S.; Julian, M.W.; Shao, G.; Abraham, S.; Liyanarachchi, S.; Macre, J.E.; Wewers, M.D.; Gavrilin, M.A.; et al. Gene expression profiling identifies MMP-12 and ADAMDEC1 as potential pathogenic mediators of pulmonary sarcoidosis. Am. J. Respir. Crit. Care Med. 2009, 179, 929-938.

25. Palchevskiy, V.; Hashemi, N.; Weigt, S.S.; Xue, Y.Y.; Derhovanessian, A.; Keane, M.P.; Strieter, R.M.; Fishbein, M.C.; Deng, J.C.; Lynch, J.P., III; et al. Immune response CC chemokines CCL2 and CCL5 are associated with pulmonary sarcoidosis. Fibrogenesis Tissue Repair. 2011, doi:10.1186/1755-1536-4-10.

26. Petrek, M.; Kolek, V.; Szotkowska, J.; du Bois, R.M. CC and C chemokine expression in pulmonary sarcoidosis. Eur. Respir. J. 2002, 20, 1206-1212. 
27. Barna, B.P.; Culver, D.A.; Abraham, S.; Malur, A.; Bonfield, T.L.; John, N.; Farver, C.F.; Drazba, J.A.; Raychaudhuri, B.; Kavuru, M.S.; et al. Depressed peroxisome proliferator-activated receptor gamma (PPAR $\gamma$ ) is indicative of severe pulmonary sarcoidosis: Possible involvement of interferon gamma (IFN- $\gamma$ ). Sarcoidosis Vasc. Diffus. Lung Dis. 2006, 23, 93-100.

28. Rosenbaum, J.T.; Pasadhika, S.; Crouser, E.D.; Choi, D.; Harrington, C.A.; Lewis, J.A.; Austin, C.R.; Diebel, T.N.; Vance, E.E.; Braziel, R.M.; et al. Hypothesis: Sarcoidosis is a STAT1-mediated disease. Clin. Immunol. 2009, 132, 174-183.

29. Moller, D.R.; Forman, J.D.; Liu, M.C.; Noble, P.W.; Greenlee, B.M.; Vyas, P.; Holden, D.A.; Forrester, J.M.; Lazarus, A.; Wysocka, M.; et al. Enhanced expression of IL-12 associated with Th1 cytokine profiles in active pulmonary sarcoidosis. J. Immunol. 1996, 156, 4952-4960.

30. Grohmann, U.; Belladonna, M.L.; Vacca, C.; Bianchi, R.; Fallarino, F.; Orabona, C.; Fioretti, M.C.; Puccetti, P. Positive regulatory role of IL-12 in macrophages and modulation by IFN- $\gamma$. J. Immunol. 2001, 167, 221-227.

31. Watford, W.T.; Hissong, B.D.; Bream, J.H.; Kanno, Y.; Muul, L.; O’Shea, J.J. Signaling by IL-12 and IL-23 and the immunoregulatory roles of STAT4. Immunol. Rev. 2004, 202, 139-156.

32. Persky, M.E.; Murphy, K.M.; Farrar, J.D. IL-12, but not IFN- $\alpha$, promotes STAT4 activation and Th1 development in murine $\mathrm{CD}^{+} \mathrm{T}$ cells expressing a chimeric murine/human Stat2 gene. J. Immunol. 2005, 174, 294-301.

33. Nishioka, Y.; Manabe, K.; Kishi, J.; Wang, W.; Inayama, M.; Azuma, M.; Sone, S. CXCL9 and 11 in patients with pulmonary sarcoidosis: A role of alveolar macrophages. Clin. Exp. Immunol. 2007, 149, 317-326.

34. Liu, J.; Guan, X.; Ma, X. Interferon regulatory factor 1 is an essential and direct transcriptional activator for interferon $\gamma$-induced RANTES/CCl5 expression in macrophages. J. Biol. Chem. 2005, 280, 24347-24355.

35. Mosser, D.M.; Edwards, J.P. Exploring the full spectrum of macrophage activation. Nat. Rev. Immunol. 2008, 8, 958-969.

36. Sica, A.; Mantovani, A. Macrophage plasticity and polarization: In vivo veritas. J. Clin. Investig. 2012, 122, 787-795.

37. Sharif, M.N.; Sosic, D.; Rothlin, C.V.; Kelly, E.; Lemke, G.; Olson, E.N.; Ivashkiv, L.B. Twist mediates suppression of inflammation by type I IFNs and Axl. J. Exp. Med. 2006, 203, 1891-1901.

38. Loza, M.J.; Brodmerkel, C.; du Bois, R.M.; Judson, M.A.; Costabel, U.; Drent, M.; Kavuru, M.; Flavin, S.; Lo, K.H.; Barnathan, E.S.; et al. Inflammatory profile and response to anti-tumor necrosis factor therapy in patients with chronic pulmonary sarcoidosis. Clin. Vaccine Immunol. 2011, 18, 931-939.

39. Agostini, C.; Meneghin, A.; Semenzato, G. T-lymphocytes and cytokines in sarcoidosis. Curr. Opin. Pulm. Med. 2002, 8, 435-440.

40. Dai, H.; Guzman, J.; Chen, B.; Costabel, U. Production of soluble tumor necrosis factor receptors and tumor necrosis factor- $\alpha$ by alveolar macrophages in sarcoidosis and extrinsic allergic alveolitis. Chest 2005, 127, 251-256. 
41. Pozharskaya, V.; Torres-Gonzalez, E.; Rojas, M.; Gal, A.; Amin, M.; Dollard, S.; Roman, J.; Stecenko, A.A.; Mora, A.L. Twist: A regulator of epithelial-mesenchymal transition in lung fibrosis. PLoS One 2009, 4, e7559.

42. Bridges, R.S.; Kass, D.; Loh, K.; Glackin, C.; Borczuk, A.C.; Greenberg, S. Gene expression profiling of pulmonary fibrosis identifies Twist1 as an antiapoptotic molecular "rectifier" of growth factor signaling. Am. J. Pathol. 2009, 175, 2351-2361.

43. Bouhlel, M.A.; Derudas, B.; Rigamonti, E.; DiFvart, R.; Brozek, J.; Haulon, S.; Zawadzki, C.; Jude, B.; Torpier, G.; Marx, N.; et al. PPAR $\gamma$ activation primes human monocytes into alternative M2 macrophages with anti-inflammatory properties. Cell Metab. 2007, 6, 137-143.

44. American Thoracic Society. Statement on sarcoidosis. Am. J. Respir. Crit. Care Med. 1999, 160, 736-755.

45. Thomassen, M.J.; Buhrow, L.T.; Connors, M.J.; Kaneko, F.T.; Erzurum, S.C.; Kavuru, M.S. Nitric oxide inhibits inflammatory cytokine production by human alveolar macrophages. Am. J. Respir. Cell Mol. Biol. 1997, 17, 279-283.

46. Livak, K.J.; Schmittgen, T.D. Analysis of relative gene expression data using real-time quantitative PCR and the $2^{-\Delta \Delta C t}$ method. Methods 2001, 25, 402-408.

(C) 2013 by the authors; licensee MDPI, Basel, Switzerland. This article is an open access article distributed under the terms and conditions of the Creative Commons Attribution license (http://creativecommons.org/licenses/by/3.0/). 